doi:10.4149/neo_2013_005

\title{
Notch1 overexpression promotes cell growth and tumor angiogenesis in myeloma
}

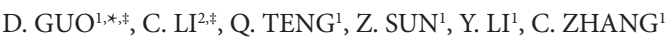 \\ ${ }^{1}$ Department of Hematology; ${ }^{2}$ Department of Orthopaedics, The Central Hospital of Taian, Taian, Shandong, P. R. China \\ ${ }^{*}$ Correspondence: dmguo001@yahoo.com.cn \\ ${ }^{*}$ Contributed equally to this work.
}

Received April 29, 2012 / Accepted June 13, 2012

\begin{abstract}
Patients with multiple myeloma (MM) have increased bone marrow angiogenesis, but the angiogenic properties of myeloma cells and the mechanism of MM-induced angiogenesis have not been completely clarified. Notch1 signal has been identified as a critical factor in the regulation of vessel formation. However, the role of Notch1 in the angiogenesis of MM is unclear. We constitutively overexpressed active Notch1 in RPMI8226 cells to explore the effect of Notch1 signaling on cell growth and tumor angiogenesis in vivo and in vitro. We found that Notch 1 overexpression promoted myeloma cells growth and increased drug resistance. Moreover, vascular endothelial growth factor (VEGF) expression was increased. Finally, our in vitro results were supported by the in vivo finding in human myeloma xenograft Nonobese diabetic/severe combined immunodeficient (NOD/SCID) models. Notch1 overexpression in MM cells resulted in up-regulation of VEGF expression, promotion of tumor growth, and increased microvessel density (MVD). Our study suggests that Notch1-induced angiogenesis is partly due to activation of VEGF pathway.
\end{abstract}

Key words: Notch1, myeloma, vascular endothelial growth factor, angiogenesis, NOD/SCID

The Notch gene family consists of structurally conserved cell surface receptors. Notch genes are involved in cell proliferation and apoptosis, which affect the development and function of many organs [1,2]. Four different Notch receptors (Notch1 to Notch4) and five ligands (JAG1, JAG2, DLL1, DLL2 and DLL4) have been characterized in mammalian cells. The binding of Notch receptors to its ligands results in proteolytic cleavage and the release of intracellular Notch (ICN), which translocates into the nucleus. The ICN associates with transcriptional factors, regulating the expression of target genes and thus plays important roles in development and cell growth $[3,4]$, including proliferation and apoptosis, alterations in Notch signaling association with tumorigenesis [5]. Data suggest that dysfunction of ICN prevents differentiation, ultimately guiding undifferentiated cells toward malignant transformation [6]. Substantial data support the conclusion that Notch1 promotes an aggressive phenotype in many tumor types [7-9].

Recently, the Delta-Notch pathway was identified as a new target in angiogenesis. This effect on angiogenesis probably occurs via several mechanisms. Most studies have suggested that Notch signaling can alter expression levels of all three
VEGF receptors in cultured endothelial cells [10-12]. Although there is accumulating evidence that Notch signaling has an essential role in vascular development and angiogenesis, less is known about the function of Notch signaling in tumor angiogenesis $[13,14]$. Moreover, there are few data available to explain the effect of Notch1 signaling activation on VEGF in tumor angiogenesis.

Therefore, in the present study, using multiple myeloma tumor cells and animal models, we investigated whether Notch1 affected VEGF expression. Surprisingly, we find that Notch1 is a key player in regulating MM cell proliferation and angiogenesis. Notch 1 acts in concert with VEGF, which is also up-regulated by Notch overexpression. Together, they drive angiogenesis. These results reveal an important new mechanistic pathway of angiogenesis and demonstrate that the Notch1/VEGF axis contributes significantly to tumor angiogenesis in myeloma.

\section{Materials and methods}

Cell culture. Human RPMI 8226 cells were cultured in suspension in Dulbecco's modified Eagle's medium (DMEM) 
(Gibco BRL, Grand Island, NY, USA) supplemented with $15 \%$ fetal-calf serum (FCS) (Gibco BRL, Grand Island, NY, USA), penicillin $(100 \mathrm{U} / \mathrm{ml})$, streptomycin $(100 \mu \mathrm{g} / \mathrm{ml})$, and $2 \mathrm{mM}$ L-glutamine (Gibco BRL, Grand Island, NY, USA). Cells were maintained in a humidified incubator at $37^{\circ} \mathrm{C}$ and $5 \% \mathrm{CO}_{2}$.

Retrovirus packaging and retroviral infection. Retroviral vectors, pMSCV-ICN/GFP (ICN, cDNA encoding a constitutively active form of Notch 1 consisting of the intracellular domain, bp 5308-7665), pMSCV-GFP, pkat (encoding a retroviral packaging plasmid), and pCMV-VSV-G (encoding the vesicular stomatitis virus G-glycoprotein) (20), were kindly provided by Dr. Chunyan Ji (Qilu Hospital, Shandong, China). HEK293T cells were plated 1 day before transfection at 40-60\% confluence in $10-\mathrm{cm}$ plates and transfected with $20 \mu \mathrm{g}$ DNA per plate for $4 \mathrm{~h}$ using the calcium phosphate precipitate method according to the manufacturer's instructions [15]. The virus particles were collected at 48 and $72 \mathrm{~h}$ after transfection, filtered through a $0.45-\mu \mathrm{m}$ filter, and then frozen at $-80^{\circ} \mathrm{C}$.

Human RPMI-8226 cells were infected with retrovirus stocks containing $8 \mu \mathrm{g} / \mathrm{mL}$ Polybrene (Sigma), centrifuged at $1,700 \times g$ for $50 \mathrm{~min}$, and then incubated at $37^{\circ} \mathrm{C}$ for $6-8 \mathrm{~h}$, washed, and cultured in fresh complete medium. A second and a third infection were conducted on subsequent days using identical procedure. Stable cell lines were generated from RPMI-8226 cells infected with recombinant retrovirus MSCV-ICN/GFP and MSCV-GFP respectively, selected by limited dilution, and designated as RPMI-8226-ICN and RPMI-8226-CON cells. RPMI-8226-ICN and RPMI-8226CON subclones were maintained in DMEM with $10 \%$ FBS for the following experiments.

Analysis of proliferation by CCK8 assay. Cells were planted at a density of 5,000 cells per well in 96-well plates. At $24,48,72$, and $96 \mathrm{~h}$ after seeding, $10 \mu \mathrm{l}$ of CCK8 (KeyGen Biotech, Nanjing, China) was added per well. After an additional 40 min incubation, color development was measured on a microplate reader at $570 \mathrm{~nm}$. For the chemotherapeutic sensitivity assay, cells were exposed to different concentration of bortezomib (Millennium Pharmaceuticals Inc., Cambridge, MA) for an additional $48 \mathrm{~h}$ and the CCK8 assay was performed as described above. The $\mathrm{IC}_{50}$ was calculated using the following formulas: $Y_{1}-Y_{2} / X_{1}-X_{2}=M ; Y_{1}-M X_{1}=B ; B-50 /-M=I C_{50}$, where $\left(X_{1}, Y_{1}\right)$ and $\left(X_{2}, Y_{2}\right)$ are two points below and above $50 \%$ inhibition rate $(X=$ drug concentration and $Y=\%$ inhibition rate) [16].

ELISA assay. To examine whether Notch 1 expression enhanced the release of VEGF by MM cells, RPMI-8226, RPMI-8226-CON and RPMI-8226-ICN cells were planted at a density of $5 \times 10^{5}$ cells per well in 24 -well plates. At $24,48,72$ $\mathrm{h}$ after seeding, culture supernatants were stored at $-80^{\circ} \mathrm{C}$ prior to analysis. VEGF specific ELISA (R\&D Systems, Minneapolis, MN USA) was performed according to the manufacturer's instructions.

Western blot analysis. Cells were lysed in lysis buffer [50 mM Tris (pH 7.5), $100 \mathrm{mM} \mathrm{NaCl}, 1$ mM EDTA, 0.5\% NP40,
$0.5 \%$ Triton X-100, $2.5 \mathrm{mM}$ sodium orthovanadate, $10 \mu \mathrm{l} / \mathrm{ml}$ protease inhibitor cocktail, $1 \mathrm{mM}$ phenylmethylsulfonyl fluoride] for $20 \mathrm{~min}$ at $4^{\circ} \mathrm{C}$. The protein concentrations were determined with the BCA Protein Assay reagent (Pierce, Rockford, IL), according to the manufacturer's instructions. Total proteins were fractionated by SDS-PAGE and transferred onto nitrocellulose membrane. Membranes were blocked with blocking buffer [0.1 M Tris (pH 7.5), $0.9 \%$ $\mathrm{NaCl}$, and $0.05 \%$ Tween-20 (TBST) containing 5\% nonfat milk powder], then incubated with appropriate primary antibodies against Notch 1 (Abcam, Cambridge, UK), HES1 (Abcam, Cambridge, UK), or VEGF (R\&D Systems, Minneapolis, MN USA), followed by incubation with horseradish peroxidase (HRP)-conjugated antibodies. All secondary antibodies were obtained from Zhongshan Golden Bridge Biotechnology (Beijing, China). The probed proteins were detected using the chemiluminescent reagents (SuperSignal West Pico West Chemiluminescent Substrate, Pierce, Rockford, IL). The bidimensional absorbance of proteins on the films were quantified and analyzed with Molecular Analyst software (Bio-Rad).

In vivo model. To investigate the in vivo effects of Notch on MM cell growth and angiogenesis, we used our stablely transfected RPMI-8226-CON, RPMI-8226-ICN and RPMI8226 cells to inoculate NOD/SCID mice (female at 4-6 weeks of age, purchased from Animal Center of Beijing, China, $\mathrm{n}=40$ ). Animals were randomly assigned to three groups with 5 mice per group: RPMI-8226-CON, RPMI-8226-ICN and RPMI-8226 group. Cells $\left(2 \times 10^{7}\right)$ suspended in $200 \mathrm{uL}$ of serum-free DMEM were inoculated subcutaneously in the flank region of mice, respectively. The mice were evaluated for tumor growth every $7 \mathrm{~d}$. The mice were sacrificed $43 \mathrm{~d}$ after tumor inoculation. The tumor tissues were fixed in $10 \%$ neutral formalin solution and embedded in paraffin block, then tissue slices were stained with hematoxylin and eosin (HE).

To investigate the in vivo effects of Notch 1 on myeloma cell drug resistance, bortezomib treatment started when tumors size averaged $1650 \mathrm{~mm}^{3}$ (day 0) in RPMI-8226CON, RPMI-8226-ICN and RPMI-8226 group. On day 0 , no marked difference was observed in tumor size between the three groups. The mice were divided into different treatment groups: RPMI-8226-ICN group treated with bortezomib, RPMI-8226-CON group treated with bortezomib, RPMI-8226 group treated with bortezomib. Bortezomib $(0.75 \mathrm{mg} / \mathrm{kg})$ were injected intravenously 2 times per week for two consecutive weeks. After the beginning of the injection, tumor sizes were measured every 3 days for two consecutive weeks using calipers, by a blinded observer. The tumor volumes $\left(\mathrm{mm}^{3}\right)$ were calculated as length $\times$ width $^{2} \pi /$ 6 . At the end of the experiment all the mice were sacrificed and the tumor weight was measured. Each treatment group consisted of five mice.

Immunohistochemical staining for micro vessel. Immunohistochemical analysis of Notch1, VEGF, and CD34 
expression were performed according to the protocol of immunohistochemistry assay kit (Zhongshan Golden Bridge Biotechnology, Beijing, China). CD34 antibody was obtained from R\&D Systems (Minneapolis, MN USA). Diaminobenzidine (DAB) was used as a chromogen to visualize blood vessels and for immunohistochemical staining. Sections were counterstained with haematoxylin. Negative controls were incubated with non-specific IgG as the primary antibody.

Vessel number was assessed using light microscopy in areas of the slide containing the highest numbers of CD34-positive small blood vessels. To quantify MVD, each slide was scanned at low power magnification $(\times 10-100)$. Three 'hot spot' areas with relatively higher number of new vessels were identified which were subsequently scanned at high power magnification $(\times 400)$. Five random fields of each 'hot spot' area were analyzed.

Densitometric and statistical analysis. The bidimensional absorbance of proteins on the films were quantified and analyzed with Molecular Analyst software (Bio-Rad). The data were reported as mean $\pm \mathrm{SD}$. Differences among 3 groups were determined by analysis of one-way ANOVA variance, followed by Newman-Keuls test for multiple comparisons, whereas differences between 2 groups were evaluated by the Student $t$ test for analysis of completely randomized 2-group designs. $P$ values less than 0.05 were considered statistically significant. Statistical analysis was performed by the SPSS 13.0 (SPSS Inc., Chicago, USA) statistical software programs.

\section{Results}

Notch 1 expression was up-regulated by retrovirus infection. We first examined Notch1 expression in RPMI-8226, RPMI-8226-CON and RPMI-8226-ICN cells by Western blot. Western blot analysis showed that the protein level of Notch1-ICN (the activated form of Notch-1) (120kD) was up-regulated in RPMI-8226-ICN cells compared with RPMI8226 or RPMI-8226-CON cells respectively (Fig. 1A and B). To confirm the Notch signaling pathway activation, HES1 expression, a known downstream target of Notch signaling, was examined. RPMI-8226-ICN cells expressed more HES1 at protein levels compared with RPMI-8226 or RPMI-8226CON cells (Fig. 1A and B).

Notch1 overexpression promoted myeloma cells growth and increased drug resistance. Because aberrant Notch signaling is highly associated with oncogenesis, the functional consequences associated with Notch1 overexpression in myeloma cells were determined. At 48, 72, and $96 \mathrm{~h}$ after seeding, RPMI-8226-ICN cells showed significantly increased cell growth rate as compared with RPMI-8226-CON $(P<0.01)$ (Fig. 2), which positively correlated with the increased Notch1 expression.

To further study whether up-regulation of Notch1 expression altered the response of MM cells to bortezomib, we examined cell viability in RPMI-8226, RPMI-8226-CON and

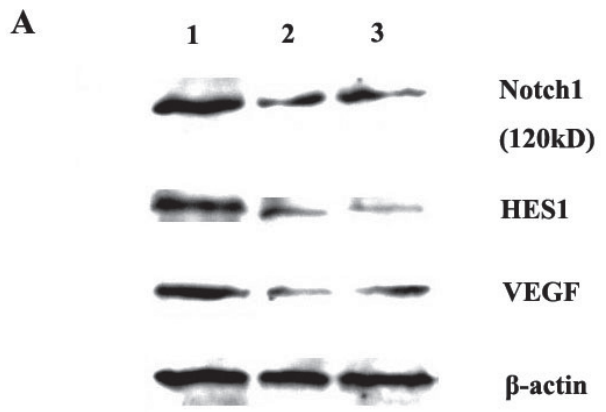

B

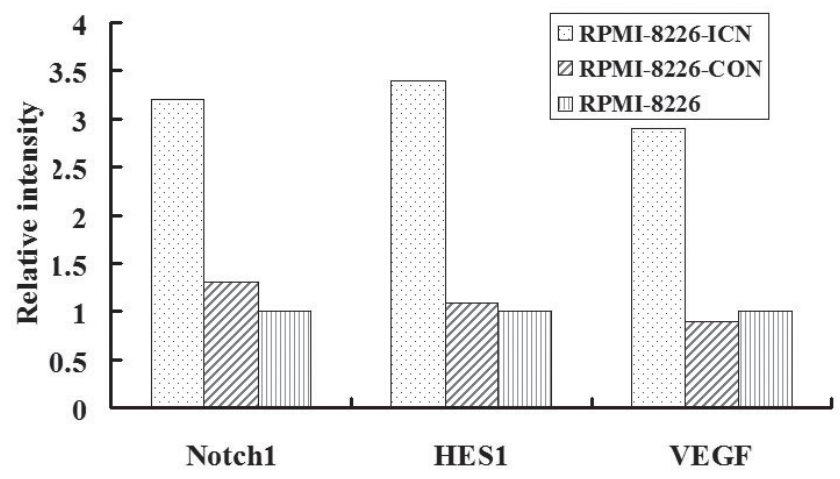

Figure 1. Effect of up-regulation of Notch1 on Notch1, HES1 and VEGF protein expression. (A) Western blot analysis was done to detect the protein levels. 1, RPMI-8226-ICN group; 2, RPMI-8226-CON group; 3, RPMI-8226 group. Results shown are representative of two independent experiments. (B) Densitometric quantification of data presented is shown. The histogram indicates the relative band intensity. Results are expressed as percentage of Notch1, HES1 and VEGF protein levels/ $\beta$ actin in the RPMI-8226 group. Columns, mean of two independent experiments.

RPMI-8226-ICN cells. Results showed that the $\mathrm{IC}_{50}$ value of bortezomib in RPMI-8226-CON group was $2.14 \mathrm{umol} / \mathrm{L}$, and was increased in RPMI-8226-ICN group, with an $\mathrm{IC}_{50}$ value

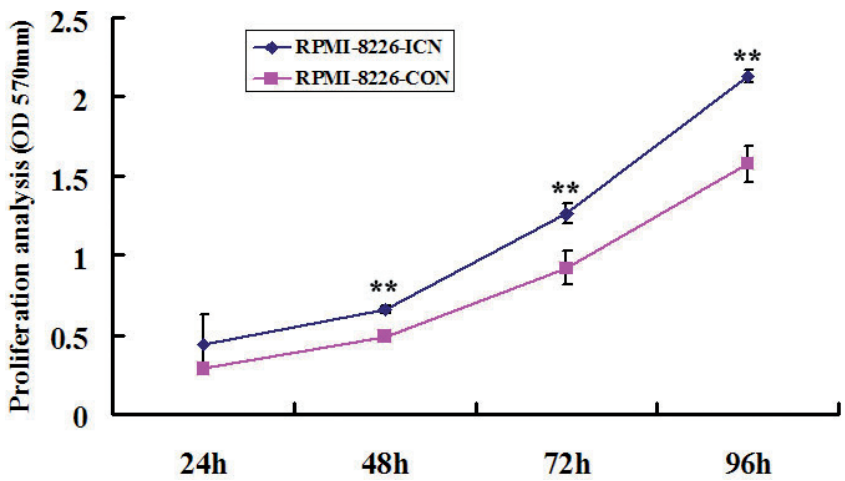

Figure 2. Effect of up-regulation of Notch1 on cell proliferation. The proliferation of RPMI-8226, RPMI-8226-CON and RPMI-8226-ICN cells was measured by $\mathrm{CCK} 8$ assay. ${ }^{*} P<0.01$ versus RPMI-8226-CON. Results are the average of three independent experiments. Error bars represent standard error of the mean. 


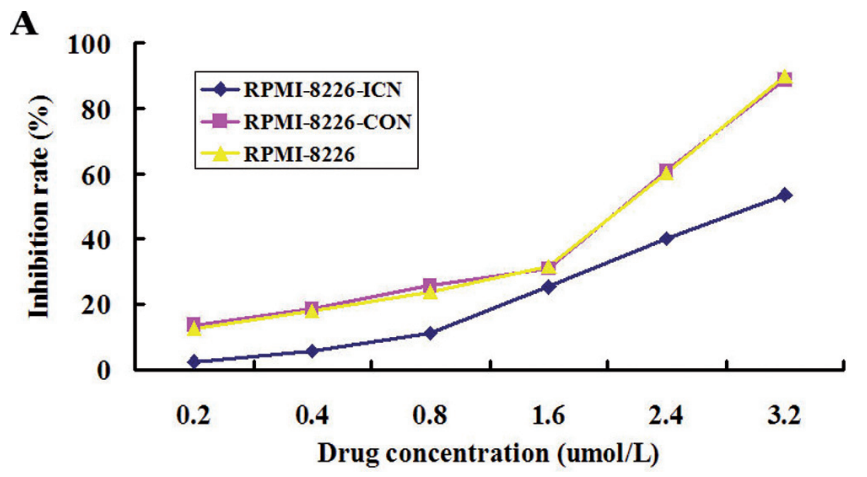

B

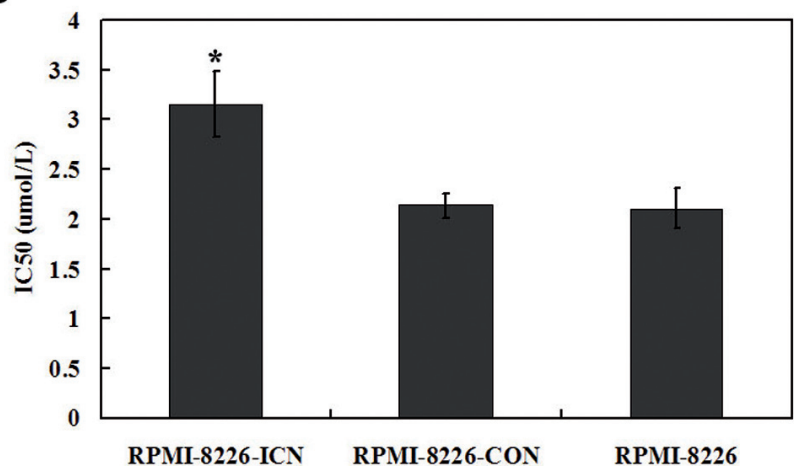

Figure 3. Effect of up-regulation of Notch 1 on MM cell sensitivity to bortezomib. (A) The RPMI-8226, RPMI-8226-CON and RPMI-8226ICN cells were treated with different concentration bortezomib for 48 $\mathrm{h}$ and CCK8 assay was performed. ${ }^{*} P<0.05$ versus RPMI-8226-CON or RPMI-8226. Results are the average of three independent experiments. (B) The $\mathrm{IC}_{50}$ was calculated using the following formulas: $Y_{1}-Y_{2} / X_{1}-$ $X_{2}=M ; Y_{1}-M X_{1}=B ; B-50 /-M=I C_{50}$, where $\left(X_{1}, Y_{1}\right)$ and $\left(X_{2}, Y_{2}\right)$ are two points below and above $50 \%$ inhibition rate $(X=$ drug concentration and $Y=\%$ inhibition rate) according to Fig. $3 \mathrm{~A} .{ }^{\star} P<0.05$ versus $\mathrm{RPMI}-$ 8226-CON or RPMI-8226.

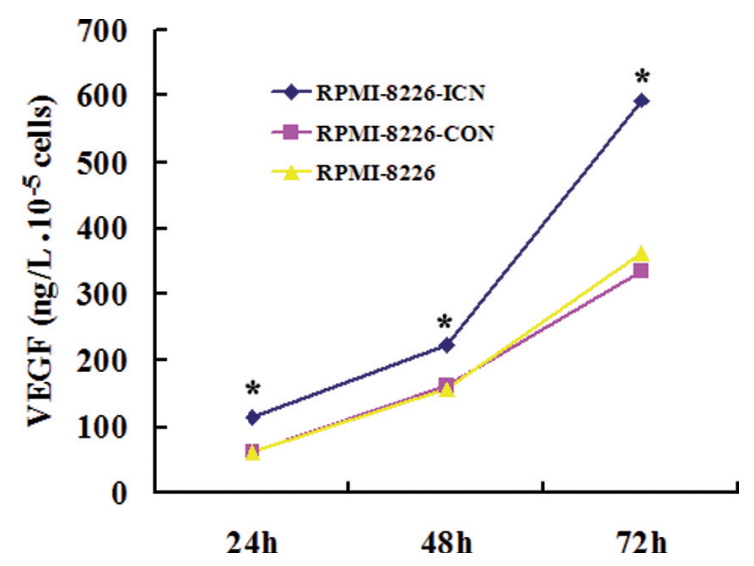

Figure 4. Effect of up-regulation of Notch1 on VEGF secretion by MM cells. Supernatants were collected and assayed for secreted VEGF protein by ELISA. The amount of secreted VEGF at various cultured times (2472 hours) was determined as described above. Results are the average of three independent experiments. ${ }^{\star} P<0.05$ versus RPMI-8226-CON or RPMI-8226. of $3.16 \mathrm{umol} / \mathrm{L}(P<0.05)$ (Fig. 3B). No marked difference was observed between RPMI-8226 group and RPMI-8226-CON group (Fig.3B). Overall, Notch1-overexpressing RPMI-8226 cells were more resistant to bortezomib.

Notch 1 overexpression induced up-regulation of VEGF expression. We further investigated whether Notch1 overexpression had any effect on VEGF induction. We found that VEGF protein level was dramatically enhanced in the RPMI8226-ICN cells (Fig. 1A and B). Most importantly, we further compared the amount of VEGF secretion at different time intervals over a period of 72 hours for the RPMI-8226, RPMI8226-CON and RPMI-8226-ICN cells. we also found that the up-regulation of Notch 1 could lead to a significant increased secretion of VEGF in supernatant (Fig. 4). The quantity of VEGF increased in RPMI-8226-ICN cells with increasing lapse of time, indicating the accumulation of the protein in the conditioned medium. In contrast, no marked difference was
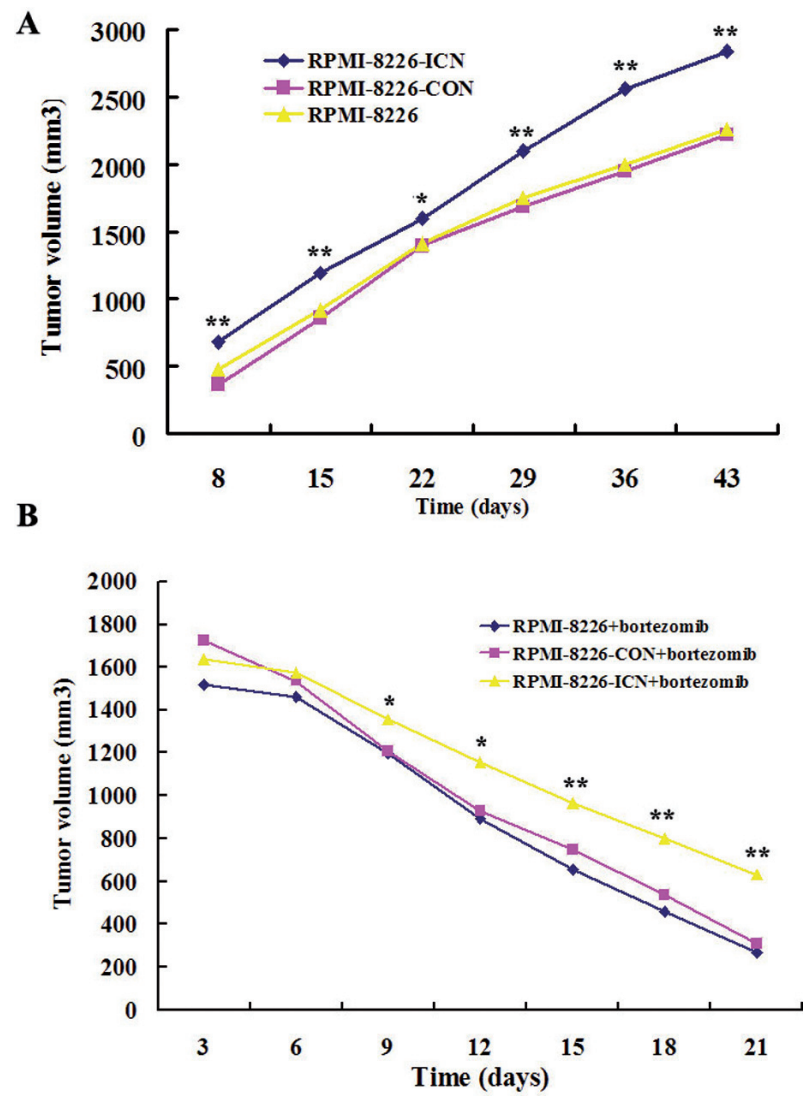

Figure 5. Effect of Notch1 overexpression on tumor volume. (A) RPMI8226-CON, RPMI-8226-ICN and RPMI-8226 cells were inoculated subcutaneously NOD/SCID mice. The mice were evaluated for tumor growth every $7 \mathrm{~d}$. The mice were sacrificed $43 \mathrm{~d}$ after tumor inoculation. ${ }^{\star} \boldsymbol{P}<0.05$ versus RPMI-8226-CON or RPMI-8226. ${ }^{* *} P<0.01$ versus RPMI-8226-CON or RPMI-8226. (B) Notch1 overexpression decreased the antitumor effects of bortezomib in vivo. Mice in different groups were treated with bortezomib. The mice were evaluated for tumor growth every $3 \mathrm{~d}$. ${ }^{*} P<0.05 \mathrm{ver}-$ sus RPMI-8226-CON or RPMI-8226 treatment group $(P<0.05) .{ }^{* *} P<0.01$ versus RPMI-8226-CON or RPMI-8226 treatment group. 

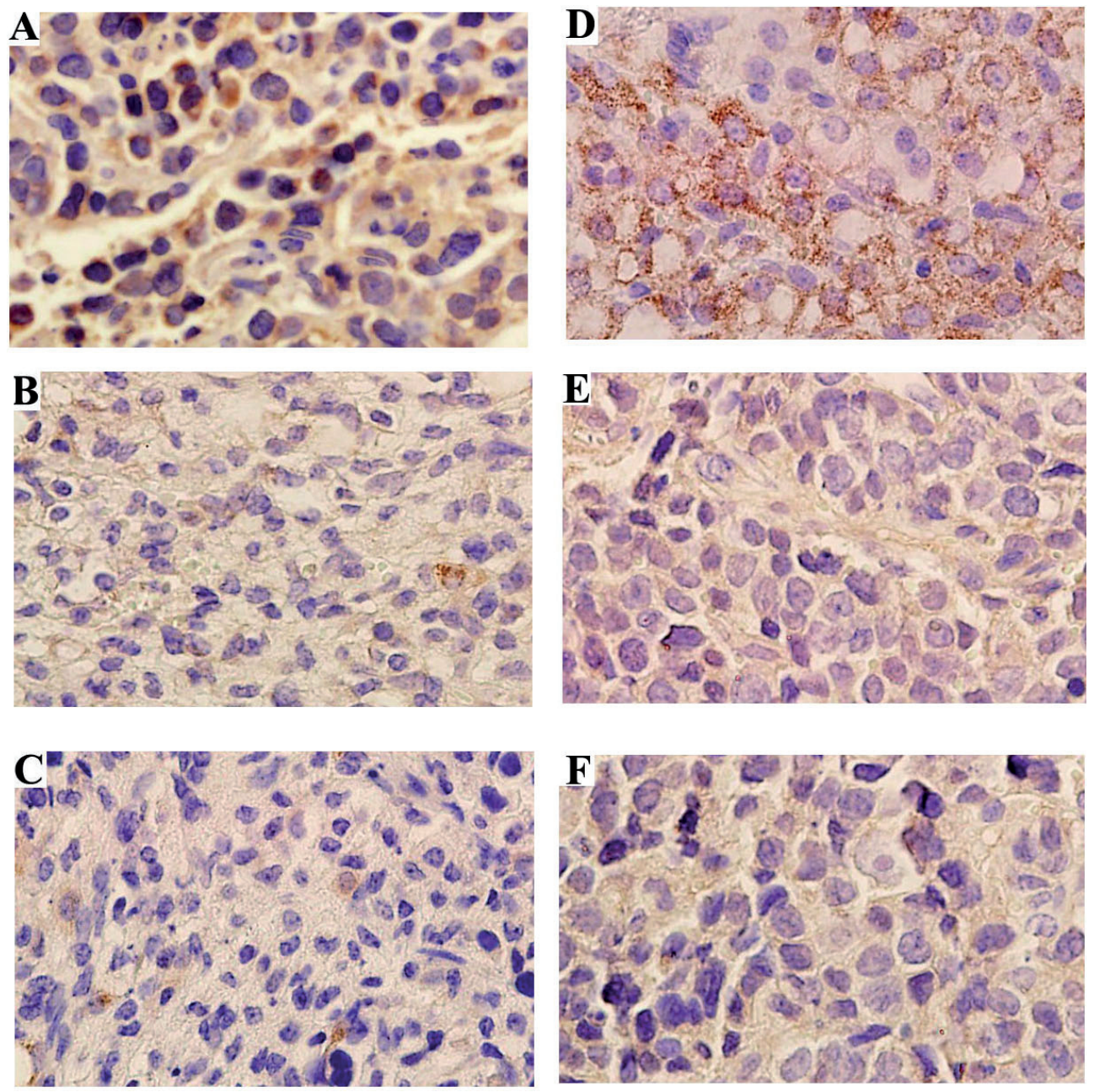

Figure 6. Effect of Notch1 overexpression on VEGF expression in vivo. RPMI-8226-CON, RPMI-8226-ICN and RPMI-8226 cells were inoculated subcutaneously NOD/SCID mice. The mice were sacrificed $43 \mathrm{~d}$ after tumor inoculation. Frozen tumor sections were used for immunostaining. Representative photographs of the tumor sections examined by immunohistochemical staining for Notch1 (A, B, C) and VEGF (D, E, F) ( $\times 400$ magnification) (RPMI8226-ICN group: A, D; RPMI-8226-CON group: B, E; RPMI-8226 group: C, F).

observed between RPMI-8226 group and RPMI-8226-CON group (Fig. 4).

Notch1 overexpression promoted tumor growth in vivo. To evaluate the effect of up-regulation of Notch 1 expression on tumor progression, RPMI-8226, RPMI-8226-CON and RPMI8226-ICN cells were inoculated into NOD/SCID mice. The total tumor burden was assessed by tumor volume. The growth rate of the implanted Notch1-overexpressing tumors was faster than that of control tumors (Fig. 5A). RPMI-8226-ICN mice displayed a significant increase in tumor size on 8 day $(P<0.01)$ (Fig. 5A). On 15 day, the mean total tumor volume in the RPMI-8226-ICN group $\left(1192 \mathrm{~mm}^{3}\right)$ was higher than that in the RPMI-8226-CON group $\left(856 \mathrm{~mm}^{3}\right)(P<0.01)$ (Fig. $5 \mathrm{~A})$. Four weeks later, On 43 day, the difference between the two groups was further enhanced (RPMI-8226-ICN vs. group RPMI-8226-CON group, $2838 \mathrm{~mm}^{3}$ vs. $\left.2222 \mathrm{~mm}^{3}\right)(P<0.01)$
(Fig. 5A). At 6 time points the mean total tumor volume did not differ between the RPMI-8226 and RPMI-8226-CON groups $(P>0.05)$.

Furthermore, compared with RPMI-8226 and RPMI8226-CON groups combined with bortezomib, there was a dramatic increase in tumor volume in RPMI-8226-ICN groups combined with bortezomib (Fig. 5B). No marked difference was observed between RPMI-8226 and RPMI-8226-CON treatment group at 7 time points $(P>0.05)$. Overall, the effect of Notch1 overexpression resulted in a substantial decrease in the sensitivity of MM cells to bortezomib in vivo.

Notch1 overexpression induced angiogenesis in vivo xenograft models. The expression levels of Notch 1 and VEGF in different groups were detected by immunohistochemistry. Tumor sections of each group were stained with anti-CD34 antibody to evaluate the microvessel density. The details 

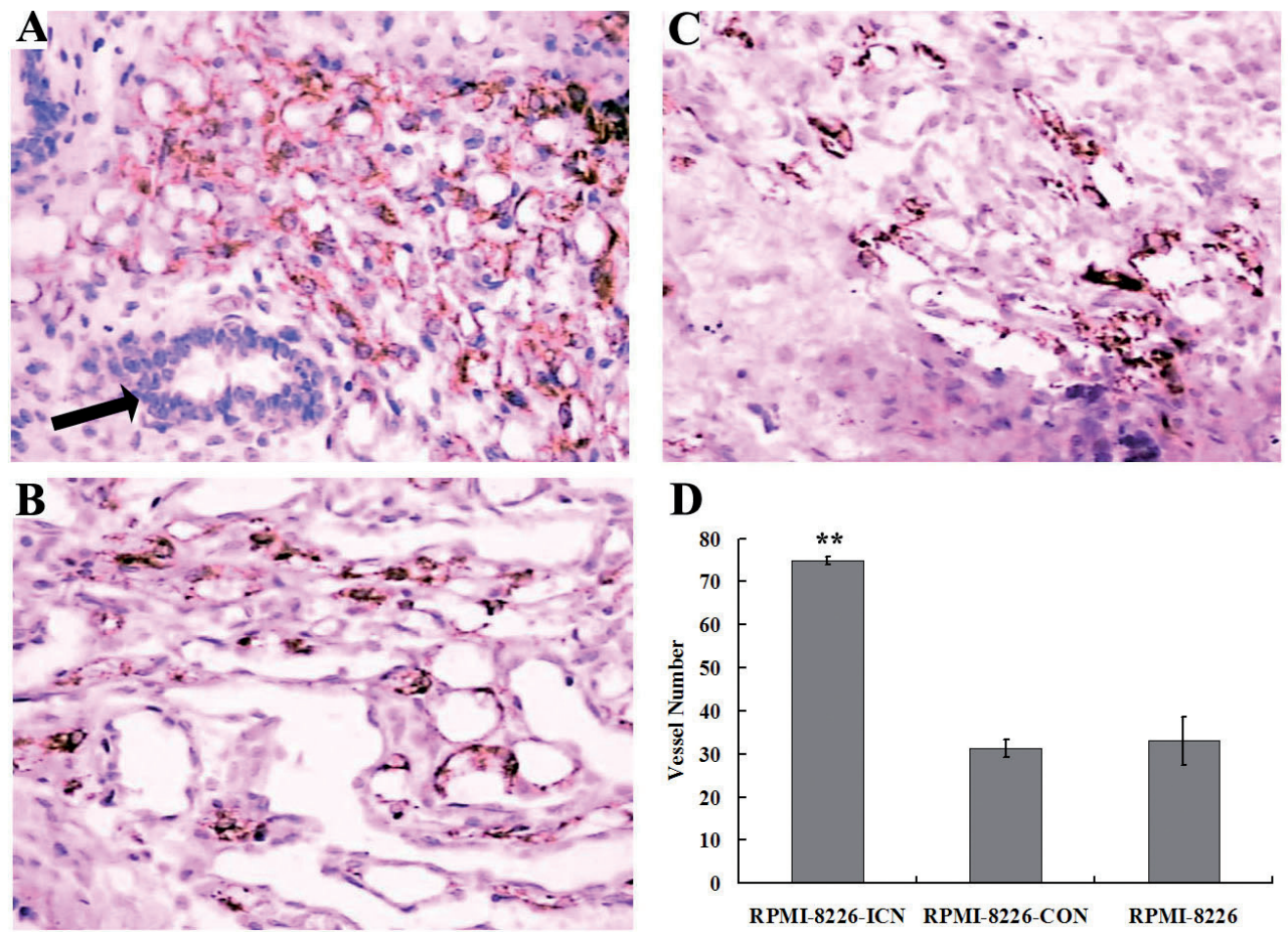

Figure 7. Promotion of MM angiogenesis by Notch1 overexpression in vivo. Representative photographs of the tumor sections examined by immunohistochemical staining for CD34 showing tumor vasculature ( $\times 400$ magnification) (A, RPMI-8226-ICN group; B, RPMI-8226-CON group; C, RPMI-8226 group). Vaculogenic mimicry (VM) (black arrow) with the appearance of lumen formed by tumor cells in RPMI-8226-ICN xenografts in NOD/SCID mice. (D) Each bar represents the average vessel number for each group, expressed as mean \pm SD. ${ }^{* *} P<0.01$ versus RPMI-8226-CON or RPMI-8226 group.

were described in Methods. Notch1 and VEGF were found to be expressed to a higher extent in RPMI-8226-ICN group as compared to other groups (Fig. 6). As shown in Fig.7, the mean MVD was increased apparently in the tumors of the RPMI-8226-ICN group compared with RPMI-8226 or RPMI-8226-CON group. Immunohistochemical analysis of the harvested tumors suggested that Notch1 overexpression was associated with increased VEGF expression and angiogenesis. These data demonstrate that Notch1 overexpression can promote tumor angiogenesis, which may play important roles in MM development in vivo.

\section{Discussion}

Notch signaling is a highly important cell signaling system, which is critically needed for the maintenance and regulation of the balance between cell proliferation, differentiation, and apoptosis. Notch1 has also been reported to be associated with malignant phenotype and to regulate the expression of a variety of important genes in some cellular responses. Furthermore, Notch signal was recently identified as a new target in angiogenesis. Therefore, studies on the interaction of Notch1 signaling activation with the VEGF pathway in tumor angiogenesis, has received increased attention in recent years. However, the precise role of Notch for MM cell growth and the interaction between Notch1 and VEGF in MM angiogenesis remains unclear.

In this study, we have shown the following: (a) Notch1 overexpression promoted myeloma cells growth and increased drug resistance; (b) Notch1 overexpression induced up-regulation of VEGF expression; (c) Notch1 overexpression promoted tumor growth in vivo; (d) Notch1 overexpression induced up-regulation of VEGF and stimulated angiogenesis in vivo. Taken together, these results further support that Notch 1 overexpression could promote tumor angiogenesis, at least in part, via up-regulation of VEGF.

It has been reported that Notch1 and its ligands were overexpressed in MM cell lines and human MM samples [17,18]. Some studies demonstrate that activation of Notch signaling induces growth arrest $[19,20]$ and apoptosis [19] in multiple myeloma. Conversely, other studies provide evidence concerning the role of Notch in B-cell malignancy, showing that active Notch actually promotes the proliferation of B-cell tumors [18, 21-22]. In the present study, we showed that myeloma cells were infected with recombinant retrovirus expressing intracellular Notch1, and up-regulation of Notch1 expression promoted MM cell growth. Recently, experimental evidence also revealed that Notch was involved in anti-cancer drug resistance, indicating that targeting Notch could be a novel therapeutic approach for the treatment of cancer by overcoming drug resistance 
of cancer cells [23]. In our previous study, we also found that Notch receptors and ligands were highly and widely expressed in human T-ALL and breast cancers $[24,25]$. Notch1 was associated with the resistance of apoptosis and down-regulation of Notch1 signaling could sensitize T-ALL and breast cancers cells to chemotherapy $[24,25]$. Bortezomib as representative of proteasome inhibitors has been licensed by FDA, but the signal pathway involved in bortezomib-induced apoptosis is not yet clear. Wang et al. [26] found that with the increase of bortezomib concentration, RPMI-8226 cell apoptosis was increased while Notch 1 expression was decreased. It was concluded that Notchl signaling pathway participated in bortezomib-inducing MM cell apoptosis [26]. In this study, we have shown that in vitro up-regulation of Notch1 expression increased bortezomib resistance of MM cells and in vivo tumor volume in the RPMI8226-CON group combined with bortezomib was higher than in the RPMI-8226-ICN group. We conclude that the possible mechanism of resistance to bortezomib could be associated with up-regulation Notch1 signaling.

Notch1 has also been reported to crosstalk with the VEGF pathway. Activated Notch receptors on endothelial cells can in turn positively (VEGF-R1, VEGF-R3) [10-12] or negatively (VEGF-R2) [11] regulate the expression of VEGF receptors in those cells. Thus, Notch on endothelial cells can provide negative feedback to reduce VEGF activity. However, it has also been reported that Notch1 signal can regulate VEGF expression. It was shown that down-regulation of Notch1 could reduce VEGF expression in pancreatic cancer and prostate cancer $[27,28]$. In the present study, we have shown that Notch1 overexpression in MM cells up-regulated VEGF expression in those cells, which stimulated angiogenesis and increased MVD. Therefore, it is possible that Notch1-induced angiogenesis is partly due to activation of VEGF pathway. However, further in-depth studies are needed to investigate the precise molecular mechanism regarding the cause and effect of relationship between Notch1 and VEGF during Notch1-induced angiogenesis of MM cells. It was reported VEGF was responsible for the development, maintenance, and progression of $\mathrm{MM}$ by promoting bone marrow angiogenesis [29]. More recently, it was shown that MVD was a poor prognostic factor in multiple myeloma [30]. Our results showed that Notch1 overexpression was associated with increased VEGF expression and MVD. However, although promising, it is still not clear whether Notch1 activation has prognostic significance in MM patients. Therefore, further studies with larger cohorts of patients are needed to evaluate the prognostic significance of Notch1 activation in MM patients.

In summary, we presented experimental evidence that strongly supported the effects of up-regulation of Notch1 on tumor growth and angiogenesis in MM. Notch1 overexpression in MM cells drived the secretion and release of VEGF which contributed angiogenesis. Finally, our findings should allow to develop new therapeutic approaches involving interference with Notch pathway as a means to block MM cell proliferation and tumor angiogenesis.
Acknowledgements: This study was supported by Shandong Province Natural Science Foundation, China (No. 2009ZRA09006, No. ZR2012HL38), Shandong Province Medical Science and Technology Development Program (No. 2011HW077) and The Central Hospital of Taian Program (No. 2012YY02).

\section{References}

[1] ROTHENBERG EV. Negotiation of the T lineage fate decision by transcription-factor interplay and microenvironmental signals. Immunity. 2007, 26: 690-702. http://dx.doi. org/10.1016/j.immuni.2007.06.005

[2] ARTAVANIS-TSAKONAS, RAND MD, LAKE RJ. Notch signaling: cell fate control and signal integration in development. Science. 30, 284: 770-776.

[3] ISO T, KEDES L, HAMAMORI Y. HES and HERP families: multiple effectors of the Notch signaling pathway. J Cell Physiol. 2003, 194: 237-255. http://dx.doi.org/10.1002/jcp.10208

[4] KAGEYAMA R, OHTSUKA T, HATAKEYAMA J, OHSAWA R. Roles of bHLH genes in neural stem cell differentiation. Exp Cell Res. 2005, 306: 343-348. http://dx.doi.org/10.1016/ j.yexcr.2005.03.015

[5] PANCEWICZ J, TAYLOR JM, DATTA A, BAYDOUN HH, WALDMANN TA, et al. Notch signaling contributes to proliferation and tumor formation of human T-cell leukemia virus type 1-associated adult T-cell leukemia. Proc Natl Acad Sci U S A. 2010, 107: 16619-16624. http://dx.doi.org/10.1073/ pnas. 1010722107

[6] WEIJZEN S, RIZZO P, BRAID M, VAISHNAV R, JONKHEER SM, et al. Activation of Notch-1 signaling maintains the neoplastic phenotype in human Ras-transformed cells. Nat Med. 2002, 8: 979-986. http://dx.doi.org/10.1038/nm754

[7] CHEN SM, LIU JP, ZHOU JX, CHEN C, DENG YQ, et al. Suppression of the notch signaling pathway by $\gamma$-secretase inhibitor GSI inhibits human nasopharyngeal carcinoma cell proliferation. Cancer Lett. 2011, 306: 76-84. http://dx.doi. org/10.1016/j.canlet.2011.02.034

[8] HUGHES DP. How the NOTCH pathway contributes to the ability of osteosarcoma cells to metastasize. Cancer Treat Res. 2009, 152: 479-496. http://dx.doi.org/10.1007/978-1-4419$\underline{0284-9 \quad 28}$

[9] GUO D, YE J, DAI J, LI L, CHEN F, et al. Notch-1 regulates Akt signaling pathway and the expression of cell cycle regulatory proteins cyclin D1, CDK2 and 21 in T-ALL cell lines. Leuk Res. 2009, 33: 678-685. http://dx.doi.org/10.1016/j.leukres.2008.10.026

[10] HARRINGTON LS, SAINSON RC, WILLIAMS CK, TAYLOR JM, SHI W, et al. Regulation of multiple angiogenic pathways by Dll4 and Notch in human umbilical vein endothelial cells. Microvasc Res. 2008; 75, 144-154. http://dx.doi.org/10.1016/ j.mvr.2007.06.006

[11] SUCHTING S, FREITAS C, LE NOBLE F, BENEDITO R, BREANT C, et al. The Notch ligand Delta-like 4 negatively regulates endothelial tip cell formation and vessel branching. Proc Natl Acad Sci U S A. 2007, 104: 3225-3230. http://dx.doi. org/10.1073/pnas.0611177104

[12] SHAWBER CJ, FUNAHASHI Y, FRANCISCO E, VORONTCHIKHINA M, KITAMURA Y, et al. Notch alters 
VEGF responsiveness in human and murine endothelial cells by direct regulation of VEGFR-3 expression. J Clin Invest. 2007, 117: 3369-3382. http://dx.doi.org/10.1172/JCI24311

[13] LI JL, HARRIS AL. Notch signalling from tumor cells: a new mechanism of angiogenesis. Cancer Cell. 2005, 8: 1-3. http:// dx.doi.org/10.1016/j.ccr.2005.06.013

[14] REHMAN AO, WANG CY. Notch signaling in the regulation of tumor angiogenesis. Trends Cell Biol. 2006, 16: 293-300. http://dx.doi.org/10.1016/j.tcb.2006.04.003

[15] HU Y, NGUYEN TT, BUI KC, DEMELLO DE, SMITH JB. A novel inflammation-induced ubiquitin E3 ligase in alveolar type II cells. Biochem Biophys Res Commun. 2005, 333: 253-263. http://dx.doi.org/10.1016/j.bbrc.2005.05.102

[16] MOUSSA O, RIKER JM, KLEIN J, FRAIG M, HALUSHKA PV, WATSON DK. Inhibition of thromboxane synthase activity modulates bladder cancer cell responses to chemotherapeutic agents. Oncogene. 2008, 27: 55-62. http://dx.doi.org/10.1038/ sj.onc. 1210629

[17] SKRTIC A, Korac P, KRISTO DR, AJDUKOVIC STOJISAVLJEVIC STOJISAVLJEVIC R, et al. Immunohistochemical analysis of NOTCH1 and JAGGED1 expression in multiple myeloma and monoclonal gammopathy of undetermined significance. Hum Pathol. 2010, 41: 1702-1710. http://dx.doi. org/10.1016/j.humpath.2010.05.002

[18] JUNDT F, PROBSTING KS, ANAGNOSTOPOULOS I, MUEHLINGHAUS G, CHATTERJEE M, et al. Jagged1induced Notch signaling drives proliferation of multiple myeloma cells. Blood. 2004, 103: 3511-3515. http://dx.doi. org/10.1182/blood-2003-07-2254

[19] ZWEIDLER-MCKAY PA, HE Y, XU L, RODRIGUEZ CG, KAMELL FG, et al. Notch signaling is a potent inducer of growth arrest and apoptosis in a wide range of B-cell malignancies. Blood. 2005, 106: 3898-3906. http://dx.doi. org/10.1182/blood-2005-01-0355

[20] NEFEDOVA Y, CHENG P, ALSINA M, DALTON WS, GABRILOVICH DI. Involvement of Notch-1 signaling in bone marrow stroma-mediated de novo drug resistance of myeloma and other malignant lymphoid cell lines. Blood. 2004, 103: 3503-3510. http://dx.doi.org/10.1182/blood-2003$\underline{07-2340}$

[21] JUNDT F, ANAGNOSTOPOULOS I, FORSTER R, MATHAS S, STEIN H, et al. Activated Notch1 signaling promotes tumor cell proliferation and survival in Hodgkin and anaplastic large cell lymphoma. Blood. 2002, 99: 3398-3403. http://dx.doi. org/10.1182/blood.V99.9.3398

[22] NEFEDOVA Y, SULLIVAN DM, BOLICK SC, DALTON WS, GABRILOVICH DI. Inhibition of Notch signaling induces apoptosis of myeloma cells and enhances sensitivity to chemotherapy. Blood. 2008, 111: 2220-2229. http://dx.doi. org/10.1182/blood-2007-07-102632

[23] WANG Z, LI Y, AHMAD A, AZMIL AS, BANERJEE S, et al. Targeting Notch signaling pathway to overcome drug resistance for cancer therapy. Biochim Biophys Acta. 2010, 1806: 258-267.

[24] GUO D, YE J, LI L, DAI J, MA D, et al. Down-regulation of Notch-1 increases co-cultured Jurkat cell sensitivity to chemotherapy. Leuk Lymphoma. 2009, 50: 270-278. http://dx.doi. org/10.1080/10428190802553257

[25] ZANG S, CHEN F, DAI J, GUO D, TSE W, et al. RNAi-mediated knockdown of Notch-1 leads to cell growth inhibition and enhanced chemosensitivity in human breast cancer. Oncol Rep. 2010, 23: 893-899.

[26] WANG H, LIU X, XU B. Proteasome inhibitor induces apoptosis and influences the expression of Notch 1 and NF-kappaB in multiple myeloma RPMI8226 cells. Zhongguo Shi Yan Xue Ye Xue Za Zhi. 2008, 16: 531-537.

[27] WANG Z, BANERJEE S, LI Y, RAHMAN KM, ZHANG $\mathrm{Y}$, et al. Down-regulation of notch-1 inhibits invasion by inactivation of nuclear factor-kappaB, vascular endothelial growth factor, and matrix metalloproteinase- 9 in pancreatic cancer cells. Cancer Res. 2006, 66: 2778-2784. http://dx.doi. org/10.1158/0008-5472.CAN-05-4281

[28] WANG Z, LI Y, BANERJEE S, KONG D, AHRMAD A, et al. Down-regulation of Notch-1 and Jagged-1 inhibits prostate cancer cell growth, migration and invasion, and induces apoptosis via inactivation of Akt, mTOR, and NF-kappaB signaling pathways. J Cell Biochem. 2010, 109: 726-736.

[29] PODAR K, ANDERSON K. The pathophysiologic role of VEGF in hematologic malignancies: therapeutic implication. Blood. 2005, 105: 1383-1395. http://dx.doi.org/10.1182/ blood-2004-07-2909

[30] MARKOVIC O, MARISAVLJEVIC D, CEMERIIKIC V, VIDOVIC A, PERUNICIC M, et al. Expression of VEGF and microvessel density in patients with multiple myeloma: clinical and prognostic significance. Med Oncol. 2008, 25: 451-457. http://dx.doi.org/10.1007/s12032-008-9066-y 